Asian Review of Social Sciences

ISSN: 2249-6319 Vol.8 No.2, 2019, pp. 35-41

(C) The Research Publication, www.trp.org.in

\title{
Commercial Surrogacy in India: An Overview
}

\author{
Neha Tiwari \\ Research Scholar, Centre for the Study of Law and Governance, Jawaharlal Nehru University, New Delhi, India \\ E-Mail: neha.twr10@gmail.com
}

\begin{abstract}
Commercial surrogacy is an arrangement in which a woman agrees to carry a person (s) child and is paid for her services which is beyond medical expenses associated with the pregnancy. It can be gestational as well as genetic. Though it has been supported on the grounds that it helps both the childless couple and the surrogate, it has also been criticized on the grounds that it exploits the surrogates. In the year 2002 commercial surrogacy was legalized in India. With time India emerged as the hub of commercial surrogacy for primarily four reasons. Firstly, low cost. Secondly, world class medical facilities. Thirdly, easily available surrogates and lastly, lenient rules and regulations. With time many cases begun to emerge in which different stakeholders were harassed due to the lack of codified laws. On 19th December 2018, the Indian state passed a bill banning commercial surrogacy. The paper attempts to trace the journey of commercial surrogacy in India.
\end{abstract}

Keywords: Surrogacy, Genetic, Gestational, Banned, Stakeholders

\section{INTRODUCTION}

Surrogacy is an arrangement in which a woman agrees to bear a baby of a person (s). Surrogacy becomes commercial when the surrogate is paid money for her services which is beyond medical expenses associated with the pregnancy. Today commercial surrogacy is a multi-billion industry, a business which is being carried out in many parts of the world and is growing at a considerable rate.

Across the world, many couples who are childless due to infertility or other health problems (for example, absence or congenital deformity of the uterus or any medical condition that makes pregnancy potentially life threatening) or are not interested in carrying a baby for various reasons are opting for Assisted Reproductive Technologies. For example, artificial insemination, In Vitro Fertilization and others. Among which gestational surrogacy is the most preferred. Before going further we need to understand surrogacy in medical terms. There are two types of surrogacy:

1. Genetic surrogacy (also known as conventional surrogacy)

2. Gestational surrogacy (also known as Host or Full surrogacy)

A. Genetic Surrogate or Traditional Surrogacy: Genetic surrogacy involves the insemination of surrogate's eggs with the intended father's sperm. Most of the times, it happens in cases where the female partner of the couple is unable to bear a child due to health problems or when a single person or homosexual couple want to have a baby. The child carries the genes of the surrogate mother. Hence, she is also the biological mother of the child.

B. Gestational Surrogate: Gestational surrogacy involves the implantation of an embryo using either the eggs and sperm of the intended parents, a donated egg fertilised with sperm from the intended father or an embryo created using donor eggs and sperm. The child doesn't carry the genes of surrogate mother as she is not his/her biological mother.

\section{COMMERCIAL SURROGACY IN INDIA}

The roots of commercial surrogacy in Indian history can be traced back to October 3, 1978; the day when Baby Kanpuriya (the world's second and India's first IVF baby) was born. The first surrogacy baby in India was delivered on 23rd June 1994. In 2004 commercial surrogacy received enormous attention when an Indian woman delivered a surrogate child for her daughter in United Kingdom. Later, Oprah featured an American couple pursuing surrogacy in India during her daytime television programme as a result of which commercial surrogacy gained more limelight.

Although the first surrogate-born baby was delivered in 1994 it was only in the year 2002, India legalized commercial surrogacy. Commercial surrogacy in India is a part of the trend known as Medical tourism. People from other countries travel to India to receive different types of medical treatments. For example, cardiac care, joint replacement or cosmetic surgery because of the low cost price. Commercial surrogacy has been specifically renamed as reproductive outsourcing. India has emerged as the hub of commercial surrogacy or the "surrogacy capital of the world" attracting couples not only from within the country but from other countries as well.

The industry of commercial surrogacy has come a long way with around 3000 clinics across India providing the service to childless couples. According to the Indian Council of Medical Research (ICMR), approximately 2000 babies are born every year through commercial surrogacy. Surrogacy is a $\$ 2.3$ billion industry in India, according to the Confederation of Indian Industry. A 2012 study backed by the United Nations found that the estimated turnover of the commercial surrogacy industry in India was to be more than $\$ 400$ million in a year (The Times of India). Growth in the number of couples opting for surrogacy and the acceptance 
of same sex marriage gave impetus to the already thriving industry.

\section{REASONS BEHIND THE EMERGENCE OF INDIA AS THE HUB}

There are primarily four reasons behind the emergence of India as the hub of commercial surrogacy. Firstly, lenient rules and regulations. Secondly, low cost. Thirdly, world class medical facilities and lastly, easy availability of the surrogates.

\section{A. Lenient Rules and Regulations}

Commercial Surrogacy was legalized in India in the year 2002. Certain guidelines were laid down by the Indian Council of Medical Research (ICMR) under National Guidelines for Accreditation, Supervision and Regulation of Assisted Reproductive Technology Clinics in India in the year 2005. The practice is carried out according to these guidelines. Some of the major guidelines are; the child born out of surrogacy should be adopted by the genetic parents, surrogacy by assisted conception to be considered for couples who cannot carry a baby to term, payment to surrogates to cover all expenses associated with pregnancy, advertisement regarding surrogacy to not be made by ART clinic, the age of the surrogate should not be more than 45 years of age, in case a relative is acting as a surrogate for a couple then the relative should be of same generation, a prospective surrogate should be medically tested to avoid any infection to the baby and neither the surrogate nor her husband should have extramarital relationship in the last six months and lastly a woman may not act as a surrogate more than thrice in her lifetime.

Often it is argued that the above mentioned guidelines are in favor of the intended parents and the ART clinics. The guidelines try to ensure that the intended parents get a healthy baby without any hassle by ensuring that the surrogates are healthy and even go to the extent to prying into their personal lives which is highly undesirable. The guidelines helped clinics to run their business without any hassle. For the surrogate there is not much in these guidelines. There is no provision of counseling. The minimum age of the surrogate has not been laid down. Although later, women between 21-35 years of age were allowed to be surrogate.

In the year 2008, ICMR came with Assisted Reproductive Technology Bill and Rules (a draft). It was more detailed in nature, paying attention to different aspects of commercial surrogacy. The suggestions made by Law Commission of India for the first time suggested commercial surrogacy to be treated like any other legal contract. An effort was made to take care of the interests of intended parents, surrogate and children born out of surrogacy arrangement. Along with couples, single people were also allowed to opt for surrogacy; who face many problems while adopting a child, surrogacy thus came as a big relief to them. Suggestions were made to secure the future of the surrogates and children born out of surrogacy arrangement as well.

On 5th August 2009, the Law Commission of India submitted its 228th report on the practice of commercial surrogacy, titled "Need for Legislation to Regulate Assisted Reproductive Technology Clinics as well as Rights and Obligations of Parties to a Surrogacy". Some of the major suggestions made were providing financial support to the child, life insurance for the surrogate, privacy to the donor as well as surrogate, prohibiting sex selective surrogacy, one of the intended parents to the donor as well and cases of abortions to be governed by the Medical Termination of Pregnancy Act 1971 only. In the year 2010 a bill was drafted. The Bill was an improvement on the last draft and a part of the bill contained more detailed rules to regulate commercial surrogacy. Rules were laid down for different stakeholders involved; the surrogates, the intended parents, the baby born out of the arrangement and the clinics providing the service. Later the bill was revised. However it could not be tabled in the Lok Sabha.

\section{B. Low Cost}

In the developed world commercial surrogacy is exorbitantly expensive. For example, in the United States of America, the cost may reach up to $\$ 80,000$. In India, the same procedure costs around $\$ 12,000$ (usually paid to a medical tourism agency or a surrogacy broker).

\section{World Class Medical Facilities}

India today has world class medical facilities due to which people from across the world are rushing to India for treatment. Additionally, India has English speaking medical staff and the cost for any treatment is lower than what is charged in the developed world. As a result of which something called "medical tourism" has emerged and is being promoted as well. Commercial surrogacy can also be called a part of this newly emerging medical tourism.

\section{Easy Availability of Surrogates}

According to a report by Government of India, 21.9\% of the total population lived below the national poverty line in the year 2011. Although India is experiencing decline in the percentage of population living below the national poverty line (In 1993, 45.3\% of the population lived below the national poverty line), yet there is a huge section of the population which is still living a life of abject poverty. According to The World Bank,

1. Since the 2000s, India has made remarkable progress in reducing absolute poverty. Between FY 2011/12 and 2015, poverty declined from 21.6 to an estimated 13.4 percent at the international poverty line (2011PPP $\$ 1.90$ per person per day), continuing the earlier trend of robust reduction in poverty. Aided by robust economic growth, more than 90 million people escaped extreme poverty and improved their 
living standards during this period. Despite this success, poverty remains widespread in India. In 2015, with the latest estimates, 176 millions were living in extreme poverty. At the higher poverty line for lower middle-income countries, half the population or 659 million people were poor. (The World Bank)

It is a well known fact that women are the most affected by poverty. According to the Beijing Platform for Action, 1995 "...while poverty affects households as a whole, because of the gender division of labour and responsibilities for household welfare, women bear a disproportionate burden attempting to manage household consumption and production under conditions of increasing scarcity." (The Beijing Declaration and Platform for Action). The women are not paid for it and their efforts goes socially unrecognized which affects their decision making capacity in the family. Poverty also affects women in other ways. There are more chances of domestic violence, marriage at an early age, sexual exploitation, lack of education. According to United Nations Women,

2. Poverty can increase violence...women and girls living in poverty face multiple forms of discrimination and face increased risk of violence as a result. Poor girls are 2.5 times more likely to marry in childhood than those living in the wealthiest quintile. Women and girls living in poverty are more vulnerable to sexual exploitation, including trafficking. And those who experience domestic or intimate partner violence have fewer options to leave violent relationships, due to their lack of income and resources. (UN Women)

Hence it would not be an exaggeration to say that in India poverty and lack of opportunities create conducive conditions for women to opt for surrogacy which pays them well. As a result of which surrogates are easily available in India. Additionally couples looking for a surrogate generally prefer a woman who is not into drugs, has her own family and India offers exactly what they are looking for.

For the above mentioned reasons India emerged as the hub of commercial surrogacy. Couples, unable to conceive naturally or because of other reasons started rushing to India for a surrogate in order to have a baby. Hence, commercial surrogacy emerged as a major economic opportunity for women with poor economic background as they were able to earn much more than they could otherwise. However, with time stakeholders started facing some major problems due to the absence of codified laws to regulate the industry of commercial surrogacy.

\section{PROBLEMS FACED BY THE STAKEHOLDERS}

The lack of codified laws has created problems for the stakeholders involved in the agreement. As argued by Cyra Akhila Choudhury, "The rate of growth in the market for these services has far out spaced their regulation. That gap has given rise to controversial situations in which the law has had to play catch-up." (Choudhury, 2015). We will discuss different problems faced by the stakeholders.

\section{A. Problems Faced By the Surrogates}

Due to lack of codified laws the surrogates face number of problems and are much more vulnerable to exploitation. The problems faced by the surrogates can be categorized into three following categories:- firstly, economic problems secondly, legal problems, thirdly health related problems and lastly social problems.

\section{Economic Problems}

Many authors argue in favour of commercial surrogacy as according to them the surrogates are paid a good amount in return of their service. However the award winning documentary Made in India tells us something else. The filmmakers explored the distribution of the money paid to the clinic or agency for providing couples with a surrogate. They found that the surrogate is paid a small percentage of the money. It is the agency and the clinic directors who benefit the most. While clinics claim to pay surrogates between $\$ 5000$ and $\$ 7000$, surrogates interviewed in the documentary said that they only received a portion of their money and sometimes as little as \$ 1, 000 .

They are unlikely to be paid the full amount in case they lose the baby. Also, there is no provision of insurance or post-pregnancy medical and psychiatric support for them.

According to the guidelines provided by ICMR, “...The surrogate mother would also be entitled to a monetary compensation from the couple for agreeing to act as a surrogate; the exact value of this compensation should be decided by discussion between the couple and the proposed surrogate mother." The guideline also states that the negotiations between a couple and the surrogate mother must be conducted independently between them. Here lies the problem. It is a common knowledge that the surrogates in India come from poor socio-economic background. Most of them are neither educated nor aware enough to strike a good deal for the service they provide. Drabiak, Wegner, Fredland and Helft in their article Ethics, Law, and Commercial Surrogacy: A Call for Uniformity have also argued that commercial surrogacy agencies attempt to reduce the financial bargaining power of potential surrogates by using both the disparities in state law and the cultural rhetoric surrounding the value of children. (Drabiak et al., 2007)

\section{Legal Problems Faced By Surrogates}

The surrogates are also not protected by strict laws as compared to the surrogates in countries like the United States of America (USA). If we study the guidelines issued by the Indian Council for Medical Research (ICMR) for the commercial surrogacy industry, we will find that the 
guidelines tries to ensure that the intended parents and the child do not have to suffer financially, physically or emotionally. However no such guidelines are there for a surrogate. Additionally there is no provision of psychological screening or legal counseling, which is mandatory in USA. Surrogates with poor economic background would be unable to afford a lawyer, if the need arises and there is no provision of a free legal help for them. For example, according to a news published in The New Indian Express on 14th July 2015, a surrogate mother who delivered twins in a private hospital on 4th July 2015 complained to police on Monday that she has been cheated by the hospital, which is paying her less than a quarter of what she claims she should be paid as compensation. A complaint was lodged by the Royala Nagar police but not a formal complaint pursuant to the mother's claims as the police said that they will verify the documents pertaining to the contract before lodging an FIR. (The New Indian Express)

\section{Health Problems Faced By the Surrogates}

The majority of the surrogates undergo caesarean for the delivery. A caesarean surgery can have harmful impact on a woman's body. For example, infection can occur at the incision site, hemorrhage, and injury to organs such as bladder and others. Apart from physical harm there can be psychological repercussion as well. The psychological impact stems from relinquishing the baby. Additionally staying away from their own family can also cause stress. Many surrogates stay away from their own family during the time of pregnancy and are rarely allowed to meet. This can trigger guilt as well as stress among the surrogates. Hence, the surrogates need to be counseled before and after their delivery to help them deal with the stress. However there is no provision for counseling in the guidelines (provided by the ICMR). Once the deal is signed they follow all the rules and regulations laid down by the clinic and the intended parents. They prioritize their interest over theirs' and their families.

\section{Social Problems}

We may find instances of a woman carrying someone else's baby in India's mythological stories. However traditionally it is considered a matter of shame in India. A woman carrying someone else's child is looked down upon, shamed and shunned by the society. For similar reasons most of the surrogates try to hide the fact that they are a surrogate, carrying someone else's baby. As a result of which surrogates and their families live under constant fear of other people discovering the pregnancy and shaming them in the society. As a result of the stigma attached to it most of the surrogates and their families keep it as a secret. Carrying someone else's child is traditionally something which is looked down upon in the Indian society. Amrita Pande in her article "At Least I Am Not Sleeping with Anyone": Resisting the Stigma of Commercial Surrogacy in India has quoted a surrogate stating,
My husband doesn't tell anyone what I am doing or where I am when I stay at this hostel. He says I've gone for work in another city. Everyone thinks this [surrogacy] is a bad thing and we [surrogates] are worse; we sell our body and then our baby. You have to be careful in a society like ours. They don't understand that we are not doing this for fun. (Pande, 2010).

Commercial surrogacy not only affects the surrogate but also her family. Merrick in the context of commercial surrogacy as practiced in the United States of America argues,

The potential psychological impact of surrogacy does not begin and end with the surrogate. It also affects other members of her family. What of the surrogate's husband? He watches his wife grow large carrying another man's child. He may participate in childbirth classes and be present for the delivery. He may be there to comfort his wife when she feels ill or is emotionally drained. He may have to pick up the load when she is too tired to care for the other children and to fulfill her responsibilities in the home. Does he also bond with the unborn child? (Merrick, 1990).

Hence, it would not be wrong to argue that commercial surrogacy has the potential to disturb the family of the surrogates which can create difficulties for them in the long run.

There is a possibility of discrimination based on caste lines. Sometimes the selection of a surrogate is also based on caste lines. Many couples prefer a surrogate of their own caste. At times caste determines the money to be paid to the surrogate. According to an agent Ramana Rao who recruits egg donors and surrogate for childless couples and fertility clinics said, "couples are very particular about the hierarchy of the prospective mother or even the surrogate carrier...a lady belonging to the higher caste with good looks can earn as much as between Rs 50,000 to 100,000 and a lady belonging to the lower caste can earn Rs 20,000." (The Global Post)

\section{B. Problems Faced By the Intended Parents}

Disappointment of intended parents is understandable who sometimes have to fight a long legal battle to get their child's custody in case of an undesirable situation. For example, if the intended parents get divorced or widowed. Several such cases have happened. For example, Ikufumi and Yuki Yamada, a Japanese couple entered into a surrogacy arrangement with an Indian surrogate, Pritiben Mehta living in Anand, Gujarat in the year 2007. The embryo was created using Yamada's sperm and egg from an anonymous Indian woman and implanted it into Mehta's womb. In June 2008 the couple divorced, a month before the baby was born. Ikufumi wanted to raise the child but his ex-wife was not willing. As a result of which a lot of confusion and legal issues emerged. Now baby Manji had three mothers- Yuki Yamada, the anonymous egg donor and 
the surrogate. However, legally none. There were no guidelines to deal with this kind of situation nor there were any law to help. As a result of which the parentage as well as nationality of Baby Manji became difficult to determine.

\section{Problems Faced by Children Born Out of Commercial Surrogacy}

Surrogacy leads to problems of citizenship, motherhood, parentage, and rights of a child. There have been occasions when children have been denied citizenship of the country of intended parents resulting in either a long legal battle (For example, in the case of a German couple with twin surrogate children or the Israeli gay couple who had to undergo DNA testing to establish parentage) or having an uncertain future in an orphanage. There have also been cases in which babies born out of a commercial surrogacy arrangement have been left by the intended parents even though they were genetically related to them. For example, an Australian couple entered into a surrogacy arrangement with an Indian woman living in India. Twins were born, a boy and a girl. However the couple decided to leave with only one of the twins as they already had one baby of their own. The decision was made on the basis of child's gender.

Apart from problems related to their citizenship children are also vulnerable to physical and psychological problems. Since majority of the surrogates undergo cesarean surgery to deliver the baby, the baby is vulnerable to health hazards like obesity, celiac disease, asthma, type I diabetes, higher sensitivity to allergens. Detachment from the woman who gave birth to them can have serious psychological impact on them.

However despite all the problems, the commercial surrogacy industry kept on expanding even though commercial surrogacy has been criticized by many. Neha Wadekar in her article Wombs for Rent: A Bioethical Analysis of Commercial Surrogacy in India called for a complete ban on commercial surrogacy long back because for her it violates the bioethical principles. She further argues "... with a free market economy, and combination of public and private healthcare sectors, a moderate or regulated version of surrogacy would be difficult to achieve. I believe that it is crucial to preserve the rights and dignities of these Indian women and that commercial surrogacy in India must be banned in order to end the potential exploitation that is occurring." (Wadekar, 2011).

Anton van Niekerku and Leize van Zyl from a moral perspective. in their article The Ethics of Surrogacy: Women's Reproductive Labour have argued that the practice of surrogacy has chances of causing moral harms to the party involved in such arrangements, as conflicts can arise over the parental rights of the baby born through such arrangement. (Niekerku and Zyl, 1995).

Clara Watson in her article 'Womb Rentals and BabySelling: Does Surrogacy Undermine the Human Dignity and
Rights of the Surrogate Mother and Child?' has denounced surrogacy. Watson argues that exploitation is commonplace in all forms of surrogacy, whether literal slavery and trafficking or the unequal balance between commissioning couple and the contracted surrogate. She justifies her argument by quoting Kasja Ekman who questions, "how can we justify a situation in which wealthy people use poor people as breeders, inject them full of hormones, take children away from them and leave pocket money in exchange?" (Watson, 2016).

However, there are many in favor of commercial surrogacy. The most common argument given in its favor is that it helps childless people by "completing" their family and helps the poor surrogates financially. Martha Nussbaum sees it as an opportunity for those women who have commercial surrogacy as the only option. She is of the opinion that the surrogates can empower themselves through commercial surrogacy. She sees no harm in using one's body to earn as all of us do that in one way or the other. She further argues that there should be contracts to secure the employment of the surrogate mothers in order to enhance their economic autonomy and personal dignity (Nussbaum, 1998).

\section{RECENT DEVELOPMENTS}

With the expansion of the industry of commercial surrogacy in India many unethical practices were reported, a public interest litigation was filed by lawyer Jayashree Wad who argued that the country has virtually become a baby factory as a large number of foreigners have been coming to India in search of a surrogate mother. (On 14th October 2015) The Supreme Court expressed concern over India becoming a top destination for commercial surrogacy. The court said that there were no laws regarding various issues related to surrogacy. Hence, the government must take a holistic view and bring in legislation. The court suggested the state to ban commercial surrogacy and directed the government to reexamine the policy which allows import of human embryo. Following the court order, the Ministry of Home Affairs in November 2015 banned foreign nationals from coming to India in search of surrogates. However, commercial surrogacy was still permitted to Indian couples.

On 21 November 2016, the government of India introduced the Surrogacy (Regulation) Bill in the lower house and proposed to ban commercial surrogacy. The bill sought to ban the practice of commercial surrogacy on the grounds of it being unethical. On 17th August 2017, the standing committee sent its report. The Bill was passed on 19th December 2018. It is now called The Surrogacy (Regulation) Act, 2018. The salient features of the bill (as given in the bill) are:-

1. No surrogacy or surrogacy procedures shall be conducted, undertaken, performed or availed of, except for the following purposes, namely:- 
a. when either or both members of the couple is suffering from proven infertility

b. when it is only for altruistic surrogacy purposes;

c. when it is not for commercial purposes or for commercialisation of surrogacy or surrogacy procedures

2. an insurance coverage of such amount as may be prescribed in favour of the surrogate mother for a period of sixteen months covering post partum delivery complications, from an insurance company or an agent recognized by the Insurance Regulatory and Development Authority established under the Insurance Regulatory and Development Authority Act, 1999;

3. no woman, other than an ever married woman having a child of her own and between the age of 25 to 35 years on the day of implantation, shall be a surrogate mother or help in surrogacy by donating her egg or oocyte or otherwise;

4. no person, other than a close relative of the intending couple, shall act as a surrogate mother and be permitted to undergo surrogacy procedures as per the provisions of this Act;

5. no woman shall act as a surrogate mother more than once in her life time:

6. the age of the intending couple is between 23 to 50 years in case of female and between 26 to 55 years in case of male on the day of certification;

7. the intending couple are married for at least five years and are Indian citizens;

8. The Central Government shall, by notification, constitute a Board to be known as the National Surrogacy Board to exercise the powers and perform the functions conferred on the Board under this Act.

9. Each State and Union territory having Legislature shall constitute a Board to be known as the State Surrogacy Board or the Union territory Surrogacy Board.

The bill as compared to the previous bills has strict laws. Undertaking commercial surrogacy, providing commercial surrogacy or its related component in any form, advertising or arranging for surrogate mother is an offence and punishable with imprisonment for a term up to ten years and fine up to ten lakh. The bill received mixed responses from different sections of the society. It was both welcomed and criticized.

Senior Advocate Beni Chaterjee has called the Bill unconstitutional and unpragmatic in nature. In his article, he has argued, "The unconstitutionality of the Bill is in the fact that there is clear differentiation in the classes of people who can and cannot apply for surrogacy. A bar on homosexuals and singles is arbitrary and violative of the Right to Equality enshrined in the Constitution as also laid down by the Apex Cout in Ajay Hasia vs Khalid Mujibsehrawade (1981) 1 SCC722." (Chaterjee 2018).

Criticising the Section 5 of the Bill, the Senior Advocate has further argued,
The above being a condition to surrogacy is impractical and unlikely to fulfill the purpose of the Bill and therefore the government is required to relook into the same as it is evidently going to lead to grave psychological distress to the child as well as to the surrogate mother as she will be having access to the child by virtue of being a relative and it will be difficult for her to truly distinguish the exact relation with the child being that of an aunt or a mother. Apart from the fact that no close relation would willingly volunteer to be a surrogate mother as it involves getting implanted with the oocytes and embryos of a relative. (ibid)

The bill has allowed couples with differently able children to opt for surrogacy. Anindita Majumdar has called it regressive. She has further argued that regulative mechanisms within altruistic surrogacy have not been clearly defined. She has argued, "By banning commercial surrogacy in favor of its altruistic avatar, the identification of 'close relatives will take on a murky turn....In an overtly patriarchal society, women are always at the receiving end of ostracism and exploitation. In facilitating altruistic surrogacy among close kin, we have to be wary of the kind of exploitation we are fostering." (Majumdar, 2018).

Livemint on its website has quoted Ranjana Kumari, Director of Centre for Social Research. She has said, "As surrogacy services were easily available, people used to hire a surrogate for having a baby, no matter if they were married, single or same sex couples as commercial surrogacy will not be an option in the near future, intended single parents or couples willing to have a baby will look at adoption to fulfill the need. This may possibly boost the dismal adoption figures in India," (Livemint).

\section{CONCLUSION}

India has emerged as the hub for commercial surrogacy primarily on four grounds:- easy availability of surrogates, world class medical facilities, low cost and lenient guidelines. As a result of which people not only from within India but also from other countries are rushing to India looking for a surrogate. Although India emerged as the hub for commercial surrogacy the stakeholders (which include the surrogate, the intended parents and the baby born out of the arrangement) continued to face problems. Surrogates face problems which are economic, social, legal and medical in nature. The major problem faced by the intended parents living in foreign land is taking the baby back to their country. Many children born out of surrogacy have faced the problem of citizenship. Despite all the hurdles the industry of commercial surrogacy has been expanding and thriving. The major argument given in its favour is that it helps both the childless couples and the surrogates. It gives the childless couple a child and helps the surrogate financially.

However commercial surrogacy has been criticised by many. The criticism is primarily based on the "exploitation" it entails of the surrogates. Many argued to levy a complete 
ban on it. The state in India tried to introduce a bill in order to regulate it under strict laws. However, the bill could not be tabled under United Progressive Alliance's government. After the Supreme Court expressed concern over India emerging as a hub of commercial surrogacy, the government of India in November 2015 banned commercial surrogacy allowing only Indian citizens and altruistic surrogacy. In the year 2016 a new bill was introduced proposing a ban on the industry. On 16th December 2018 the bill was passed by Lok Sabha according to which only altruistic surrogacy is allowed for Indian citizens. Only a close relative of the couple can act as a surrogate. Surrogacy for commercial purpose cannot be practiced anymore.

\section{REFERENCES}

[1] Chaudhary, \& Akila Cyra. (2015). The Political Economy and Legal Regulation of Transnational Commercial Surrogate Labour. Vanderbilt Journal of Transnational, 48(1), 1-65.

[2] Chaterjee, Beni. (2018, December 29). Government should not be in haste to implement surrogacy laws. Sunday Guardian Times. Retrieved from: https://www.sundayguardianlive.com/news/ government-shouldnt-haste-implement-surrogacy-laws

[3] Choudhary, Amit Anand. (2015, October 15). SC Surrogates Ban on Commercial Surrogacy. The Times of India. Retrieved fromhttps://timesofindia.indiatimes.com/india/SC-suggests-ban-oncommercial-surrogacy/articleshow/49365734.cms

[4] Drabiak, K, Wegner C, Fredland V \& Helft, PR (2007). Ethics, Law, and Commercial Surrogacy: A Call for Uniformity. The Journal of Law, Medicine and Ethics, 35(2), 300-309. Retrieved from: https://doi.org/10.1111/j.1748-720X.2007.00139.x

[5] Majumdar, Anindita. (2018, December 24). What is Altruistic Surrogacy. The Hindu. Retrieved from: https://www.thehindu.com/ opinion/op-ed/what-is-altruistic-surrogacy/article25814445.ece

[6] Merrick, Janna C. (1990). Selling Reproductive Rights: Policy Issues in Surrogate Motherhood. Politics and the Life Sciences, 8(2), 161172. Retrieved from: https://doi.org/10.1017/S0730938400009709
[7] Ministry of Statistics and Programme Implementation. (2018). India in Figures. India

[8] Niekerk, Anton van \& Zyl, Liezk van. (1995). The Ethics of Surrogacy: Women's Reproductive Labour. Journal of Medical Ethics, 21(6), 345-349.

[9] Nussbaum, \& Martha C. (1998). Whether from Reason or Prejudice: Taking Money for Bodily Services. The Journal of Legal Studies, 27(S2), 693-723.

[10] Pande, \& Amrita. (2010). At Least I am Not Sleeping with Anyone: Resisting the Stigma of Commercial Surrogacy in India. Feminist Studies, 36(2), 292-312

[11] Poverty and Equity Data Portal. (n.d). The World Bank. Retrieved from http://povertydata.worldbank.org/poverty/country/IND

[12] Rai, S. (2010, September 21). Designer babies, with an Indian twist. Public Radio International. Retrieved from: https://www. pri.org/ stories/2010-09-21/designer-babies-indian-twist

[13] Sharma, \& Neetu C. (2018, December 20th). Lok Sabha passes surrogacy bill in likely boost for adoption in India. Livemint. Retrieved from: https://www.livemint.com/ Politics/hARv5 G5wm1 Fo2QQqQ43I3J/Lok-Sabha-passes-surrogacy-bill-in-likely-boost-foradoption.html

[14] Surrogate Mom Alleges Underpayment by Private Hospital After Delivery of Twins. (2015, July 14th) The New Indian Express. Retrieved from: http://www.newindianexpress.com/cities/ chennai/ 2015/jul/14/Surrogate-Mom-Alleges-Underpayment-by-PrivateHospital-After-Delivery-of-Twins-783625.html

[15] The Beijing Declaration and Platform for Action. (n.d) UN Women. Retrieved from: http://www.un.org/womenwatch/daw/beijing/ platform/

[16] Wadekar, \& Neha. (2011). Wombs for Rent: A Bioethical Analysis of Commercial Surrogacy in India. Tuftscope The Journal of Health, Ethics and Policy (online), 10(3), Retrieved from: http://www. neha wadekar.com/wp-content/uploads/2015/01/Neha-Wadekar_WritingSample-1_Surrogacy- Published.pdf

[17] Watson, \& Clara. (2016). Womb Rentals and Baby-Selling: Does Surrogacy Undermine the Human Dignity and Rights of the Surrogate Mother and Child. The New Bioethics, 22(3), 212-228. Retrieved from: https://doi.org/10.1080/20502877.2016.1238582

[18] Women and Poverty. (n.d) .UN Women. Retrieved from: http://www. unwomen.org/en/news/in-focus/end-violence-against-women/2014/ poverty 